\title{
Recursos digitais como motivação para aprendizagem: vivência da exposição interativa brincando com o sol
}

\author{
Bianca Martins (UniCarioca | NUCAP | PUC-Rio), \\ Maira Roberto (UniCarioca | NUCAP), \\ Dyene C. Verde (UniCarioca | NUCAP), \\ Joaquim Santos (UniCarioca | NUCAP), \\ André C. Espírito Santo (UniCarioca | NUCAP | IEN | CNEN), \\ Antônio C. A. Mól (UniCarioca | NUCAP | IEN | CNEN), \\ Ana Paula Legey (UniCarioca | NUCAP)
}

\section{Resumo}

Este artigo apresenta a concepção e realização da exposição interativa Brincando com o Sol, desenvolvida pelo NUCAP - Núcleo de Computação Aplicada do Centro Universitário Carioca (UniCarioca). No trabalho, discute-se a relevância do uso de recursos digitais e dos espaços interativos para a aprendizagem contemporânea. São apresentados o relato dos princípios norteadores do processo de Design da exposição interativa e o processo de desenvolvimento de cada atividade digital interativa da exposição. São também discutidas e analisadas duas situações com cenários bem distintos em que a exposição interativa foi experimentada pelo público. Por fim, são analisadas as lições aprendidas nesta vivência e de que forma o público as avaliou.

Palavras-Chave: Aprendizagem; recursos digitais; exposição interativa; design.

\begin{abstract}
This article presents the conception and realization of the interactive exhibition "Playing with the Sun", developed by NUCAP - Núcleo de Computação Aplicada do Centro Universitário Carioca (UniCarioca). So, the relevance of the use of digital resources and interactive spaces for contemporary learning is discussed. We present the report of the guiding principles of the Design process of the interactive exhibition and the development process of each interactive digital activity of the exhibition. Two situations with very distinct scenarios in which interactive exposure was experienced by the public are also discussed and analyzed. Finally, we analyze the good practice learned in this experience and how the public evaluated them.
\end{abstract}

Keywords: Learning; Digital resources; Interactive exhibition; Design.

\section{Introdução}

O Núcleo de Computação Aplicada da UniCarioca (NUCAP), formado por alunos e pesquisadores de áreas interdisciplinares (Computação, Pedagogia e Design), vem propondo pesquisas relacionadas a sua linha principal, intitulada Novas Tecnologias Digitais na Educação, como forma de aproximar a tecnologia que já permeia o cotidiano, na sociedade contemporânea, instigando, desta forma, modos mais pertinentes e motivadores de se ensinar e aprender.

O viés de atuação do NUCAP pauta-se na articulação dos três eixos que sustentam as competências promovidas em qualquer processo de aprendizagem: conhecimentos, procedimentos e comportamentos (ZABALLA, 2010). Ou seja, o objetivo é oferecer aos sujeitos que participam das ações estratégias lúdicas de aprendizagem, que fazem 
uso de recursos digitais, com a intenção de favorecer a articulação dinâmica de aspectos cognitivos, práticos e afetivos na construção do conhecimento.

Dentro deste contexto, acredita-se que a partir de projetos que promovam imersão em experiências que integram diferentes saberes e atores, as universidades podem contribuir pesquisando formas mais pertinentes de ensino-aprendizagem atentas aos desejos, necessidades e ao perfil socioafetivo dos aprendentes, para propor abordagens alternativas às fragilidades educacionais existentes.

Indo além, acredita-se, ainda, que as atividades digitais propostas podem ser ressignificadas para o contexto escolar, uma vez que foram concebidas com essa premissa de adaptabilidade a contextos similares.

Com base neste paradigma de ensino-aprendizagem - que articula os três eixos citados acima -, esta exposição interativa teve como propósito contribuir para o uso dos Recursos Digitais na Educação, com o objetivo de que estes sejam desenvolvidos/adaptados e incorporados como mediadores oportunos e lúdicos de um aprendizado efetivo.

\section{Fundamentação teórica}

Conforme o relatório técnico da Associação Brasileira para Educação à Distância (ABED, 2012), a inclusão de jogos e/ou narrativas digitais interativas em contextos educacionais ainda gera muita polêmica entre professores e em praticamente toda a sociedade. Concebidos como atividade lúdica, os jogos são bem aceitos em ambientes educacionais como recreação e como incentivadores do desenvolvimento de habilidades, principalmente, psicomotoras. Contudo, não há divergência quanto à capacidade dos jogos de instigar o interesse do jogador e apresentar desafios que o motivam a conhecer seus limites e as possibilidades de superá-los: a motivação dos jogadores é superar o desafio imposto pelo jogo. Dependendo de suas variantes, os jogos podem exigir um ou vários jogadores, podem ocorrer em um mesmo local físico ou ainda em um espaço virtual.

A ABED (2012) comenta que são inúmeras as facilidades proporcionadas pelas tecnologias que já integram o cotidiano de grande parte das pessoas em variadas partes do mundo. Novos usos e apropriações das tecnologias da informação e comunicação - TICs - surgem a cada momento, numa demonstração de que os sujeitos convivem com estes recursos digitais ampliando suas possibilidades de formas inusitadas. Os smartphones e computadores possibilitam o acesso à cibercultura e, a partir daí, estão à disposição recursos que facilitam as tarefas diárias, a interação e comunicação com outras pessoas e as oportunidades de diversão.

Santaella (2013) descreve o leitor imersivo como um sujeito que navega em telas e programas de leituras, por meio de um universo de signos evanescentes e eternamente disponíveis. Conforme a autora, por estar cognitivamente em estado de prontidão, esse leitor conecta-se entre nós e nexos, seguindo roteiros multilineares e labirínticos, que ele próprio ajuda a construir ao interagir com os nós que transitam entre textos, imagens, documentação, músicas, vídeo, etc. Através de saltos que vão de um fragmento a outro, esse leitor é livre para estabelecer sozinho seu caminho informacional.

Conforme a ABED (2012), é possível afirmar que, em sua maioria, os professores não são leitores imersivos, diferentemente de seus alunos, que o são. Existem também aqueles professores que apresentam resistências ou até mesmo são contrários ao uso de tecnologias em ambientes educativos. Ou seja: o processo de aprendizagem levado a cabo pelos leitores imersivos é diferente daquele de seus professores. O perfil dos alunos mudou muito diante do acesso à cibercultura favorecido pelas TICs. O interesse despertado pelos cursos online cresce em virtude das facilidades que oferecem ao aluno de estudar onde e quando lhe for mais conveniente, e os cursos com maior aceitação são aqueles que apresentam os conteúdos de forma atrativa e interativa (ABED, 2012).

\section{Jogos e aprendizagem}

Conforme Winnicott (1975), é no brincar, e talvez apenas no brincar, que a criança ou adulto fruem sua liberdade de criação. O ser humano precisa brincar como uma necessidade que vai muito além da diversão: 
brincar, ou seja, interagir com objetos e desafios concretos ou virtuais, promove o desenvolvimento de sua subjetividade (Mamede-Neves, 1996). Consequentemente, brincar promove a maturação das competências cognitiva, psicomotora e afetiva; ou seja: brincar é aprender.

Conforme Kishimoto (1998), os jogos desenvolvem, além da cognição por meio da construção de representações mentais, também a afetividade, as funções sensórias e motoras e a área social, ou seja, as relações entre os alunos e a percepção das regras.

Os jogos e as narrativas digitais favorecem o processo de aprendizagem devido aos desafios crescentes que apresentam. Macedo (2000) informa que todo jogo tem uma situação-problema (objetivo) que poderá ser solucionada ou não pelo sujeito (resultado do jogo), devendo este obedecer a um sistema de regras que determina os limites de sua ação. $\mathrm{O}$ autor frisa que os jogos estimulam, despertam a curiosidade e a criatividade, desenvolvem a capacidade de concentração e raciocínio e proporcionam uma maneira mais prazerosa de aprender.

\section{A Realidade Virtual}

A Realidade Virtual (RV) vem sendo considerada uma importante fonte de comunicação e está cada vez mais presente no cotidiano e nos objetos de aprendizagem (OLIVEIRA et al., 2015, SALAZAR et al., 2015, LEGEY et al., 2015; LEGEY et al., 2013a, 2013b, CHELLES et al., 2012, FREITAS et al., 2011). O uso de técnicas de realidade virtual permite desenvolver ambientes onde os sujeitos estão imersos em cenários criados por meio de projeções 3D (Pimentel e Teixeira, 1995). Para a aprendizagem de situações específicas, como é o caso de determinados procedimentos usados na área da saúde, discute-se que a imersão em realidade virtual é mais eficiente do que o uso de recursos de mídias tradicionais, como os vídeos 2D, por exemplo (VENDRUSCOLO et al., 2005).

Nesse sentido, os vídeos 3D e os jogos baseados em RV, concebidos por tecnologias que reproduzem um alto grau de realismo, podem ser vistos como ferramentas inovadoras de aprendizagem, mas, acima de tudo, como recursos que podem contribuir para o aprendizado de assuntos em que os métodos tradicionais não estão atingindo o objetivo.

\section{Jogos digitais}

Segundo Mattar (2009), o aprendizado baseado em jogos digitais está fundamentado em duas premissas: 1. Os aprendizes possuem características essenciais que os diferem daqueles da geração anterior; e 2. São fruto de uma geração que experimentou, enquanto crescia, uma forma radicalmente nova de jogar através de computadores e videogames. $\mathrm{O}$ autor também comenta que o conhecimento das características e potencialidades dos alunos é importante para a escolha ou desenvolvimento de jogos mais adequados à construção de uma determinada competência. $\mathrm{O}$ jogo, quando bem construído e aplicado, contribui para a aprendizagem colaborativa, na qual todos têm a oportunidade de aprender e ensinar.

\section{Gamificação}

Os estudos e projetos desenvolvidos pelo NUCAP também incorporam estratégias de gamificação aos jogos digitais para motivar a aprendizagem. Conforme a MJV (2015) - empresa especializada no desenvolvimento de jogos com esta abordagem -, a estratégia de gamificação parte da constatação de que seres humanos são atraídos por jogos. Ao longo dos séculos, praticamente todos os povos tiveram jogos como pilares importantes de suas sociedades. Nos dias de hoje, aproximadamente 3 bilhões de horas são dispensadas coletivamente por semana em jogos online apenas, o que reforça a importância social, cultural e também econômica dos games na vida de centenas de milhões de pessoas. Segundo a empresa MJV (2015), a gamificação se apropria dos 
mecanismos de engajamento utilizados nos jogos para resolver problemas práticos. Logo, ainda que em alguns casos a diversão esteja em evidência, o objetivo final da gamificação não é entreter e sim despertar o engajamento de um determinado público para uma causa específica. No caso da exposição interativa em questão, foi usada a gamificação para motivar as crianças a perceberem os benefícios do Sol para a vida e a geração de energia na Terra.

\section{Espaços interativos de divulgação científica}

Sabe-se que os ambientes formais de ensino não são os únicos locais onde as pessoas aprendem. Nesse sentido, os espaços, museus e centros de ciência podem complementar a educação formal, possibilitando a ampliação e o aprimoramento do conhecimento científico de estudantes e do público em geral. Este é um campo fértil para diferentes práticas educativas.

A relação entre espaços de divulgação científica e a sociedade, naturalmente, evoluiu conforme o espírito do tempo de cada época, adotando, portanto, diferentes formas de comunicação e interação com o público, para promover a aprendizagem dos conhecimentos científicos.

Os chamados museus de primeira geração (século XVIII, pós-Revolução Francesa) eram apenas locais para colecionar e apresentar objetos. A interação e comunicação, nessa época, assemelhava-se àquela da escola tradicional: uma pedagogia tradicional traduzida por meio de uma forma autoritária de expor o conhecimento e pelo papel passivo conferido ao público. (Friedman, 2007)

Os chamados museus de segunda geração (séculos XIX e XX) já se apresentam de forma mais convidativa à participação e interação do público com a exposição em questão (FRIEDMAN, 2007). Nesse tipo de museu, são apresentadas exposições para contemplar a tecnologia industrial. As instituições expõem aquilo que vem ao encontro das necessidades da indústria e das universidades e aproveitam para oferecer treinamento técnico. Contudo, pode-se dizer que, por este aspecto, estas exposições são influenciadas por princípios da pedagogia da Escola Nova. O tecnicismo educacional surge na década de 60 à sombra do progressivismo, vindo a se destacar como uma tendência. Pode ser identificada, por exemplo, pelo uso de alguns recursos interativos que apresentam uma única resposta certa, que era reforçada ao final da atividade. Alguns pesquisadores propunham que houvesse a interação do público com os artefatos apresentados. Os visitantes eram estimulados a acionar manivelas e apertar de botões (MCMANUS, 1992).

Os museus de terceira geração (século XX) assumem a preocupação com o letramento científico, ou seja: o sujeito constrói seu próprio conhecimento e dá sentido a este aprendizado em seu cotidiano (CAMBRE, 2015). Para Cazelli et al. (1999), a proposta de comunicação e interação, nessas instituições de terceira geração, segue a tendência das propostas pedagógicas contemporâneas, enfatizando o protagonismo do sujeito e seu papel ativo na formação de seu próprio conhecimento e no conhecimento coletivo de sua comunidade.

Os de quarta geração (século XXI) são recentes e buscam respeitar o indivíduo, esperando-se que este seja mais participativo no processo e possa aprender a criticar, refletir e a responder questões da sociedade, entendendo o processo intercultural a que a sociedade está imersa (PADILLA, 2001). Este autor comenta ainda que é preciso entender o público para preparar uma exposição que se comunique com sua realidade e que permita a ele interagir. Além disso, estas exposições devem ainda ser palco, de forma democrática, para toda a família, que inclui um público-alvo de diferentes idades e com intenções e interesses e diversos.

A pesquisa e as práticas educativas que ocorrem em exposições em centros de ciências e museus de ciências têm se tornado mais recorrentes. Os museus vieram mudando ao longo do tempo, e muitos deixaram de ser um simples espaço de apresentação de artes para ser uma extensão da sala da aula (CAZELLI, 2010). E, de fato, novas estratégias são utilizadas para se tentar tornar o conhecimento científico mais presente de forma acessível e democrática para qualquer público que visite estes espaços de divulgação científica. Vieira et al. (2005) apontaram em seus estudos que os espaços destinados à divulgação científica devem estimular a curiosidade dos visitantes e conferem a oportunidade de suprir, pelo menos um pouco, as carências das escolas, que muitas vezes não dispõem de laboratórios, recursos audiovisuais, ferramentas, tão importantes para estimular 
a aprendizagem. Segundo Ficheman et al. (2008), o público que frequenta museus de ciências na sociedade contemporânea deve ser ativo, pois experimenta e/ou interage de forma lúdica com artefatos científicos.

\section{Design e práticas educativas}

Martins (2007, 2015, 2016, 2017) desenvolve estudos relacionando o pensamento criativo do Design ao processo de aprendizagem, partindo do princípio de que o modo pelo qual os designers problematizam e buscam soluções para situações complexas configura certo tipo de inteligência que pode ser proveitosamente utilizada como prática educativa, visando preparar os estudantes para os desafios da vida adulta. Ou seja, tanto o processo de elaboração como também o resultado das atividades interativas desenvolvidas partiram das premissas inerentes aos projetos de Design: imaginar soluções prototipando ideias em cooperação com os usuários; utilizar o pensamento projetual como problematização multidimensional buscando articular adequadamente questões estéticas, simbólicas e funcionais e estratégias de gestão do trabalho em equipe.

\section{Objetivo da exposição interativa}

A exposição interativa Brincando com o Sol, desenvolvida pela equipe do NUCAP, foi fruto de um projeto de pesquisa fomentado pelo MCTI/CNPQ/SECIS/InstitutoTIM, coordenado por Legey, A.P. - PQ2 DCCNPq, para homenagear o Ano Internacional da Luz (Chamada - Atividades de Divulgação Científica Voltadas Ao Ano Internacional Da Luz), e foi vivenciado na Semana Nacional de Ciência e Tecnologia (SNCT) que ocorreu em outubro de 2016 em dois locais distintos: Colégio Pedro II (Unidade São Cristóvao I) e no lounge da UniCarioca (Unidade Rio Comprido).

A exposição teve como propósito divulgar os benefícios da aprendizagem por meio dos recursos digitais, levando em consideração as características dos museus de terceira e quarta geração. A equipe interdisciplinar do NUCAP - composta por pedagogos, informatas, engenheiros e designers - idealizou uma exposição interativa com o tema $O$ Sol como fonte de luz e energia. O público prioritário deste evento eram os estudantes do Ensino Fundamental 1, uma vez que este é um tema recorrente nos Parâmetros Curriculares Nacionais (PCNs) deste segmento.

Após ser implementada, a exposição realizou-se por meio de atividades que se integravam através de um percurso fixo a ser trilhado pelo público. Ao vivenciar cada atividade interativa, cada participante era instigado a aprender que o Sol é uma fonte de luz e de energia elétrica e a importância disso em nossas vidas. As atividades incluíam narrativas digitais $3 \mathrm{D}$, holografia, jogos digitais e atividades imersivas e interativas incluindo realidade virtual.

\section{Metodologia}

\section{Sobre o processo de design da exposição e dos recursos digitais educativos}

O processo de design da exposição como um todo e também das atividades interativas foi integralmente desenvolvido, de abril a setembro de 2016, pela equipe interdisciplinar do NUCAP, que reúne, como mencionado, pedagogos, informatas, engenheiros e designers. As primeiras ideias, assim como o desenho do percurso interativo da exposição, surgiram a partir de consecutivos processos de brainstorming e geração de propostas esboçadas em papel. Uma vez tendo definido o conceito norteador da exposição e seu percurso, teve início a elaboração do conceito gráfico e interativo das atividades a serem desenvolvidas.

Foram montadas as equipes de projeto procurando valorizar as experiências prévias dos bolsistas de iniciação científica no desenvolvimento de recursos digitais. Por isso, as equipes procuraram, sempre que possível, diversificar as expertises, mesclando designers, informatas e pedagogos. Logo, cinco equipes de projeto 
foram compostas pelos vinte e dois bolsistas atuantes no NUCAP, naquela época. Assim, desenvolveram-se protótipos digitais das atividades em softwares gráficos que, por fim, foram aprimorados a partir de critérios de validação em amplos aspectos (estética, interação, jogabilidade, usabilidade, dentre outros).

Como o propósito da exposição interativa era instigar a aprendizagem por meio do uso de recursos lúdicos, também foram planejadas atividades "não digitais", nas quais os visitantes deveriam exercitar a perspectiva da autoria, produzindo colagens e protótipos que cumpririam um duplo papel: estimular o registro do conhecimento aprendido através do uso de múltiplas linguagens e fazer com que o visitante pudesse levar consigo um pedaço da exposição e do conhecimento aprendido.

As atividades digitais foram construídas a partir de recursos diversificados, e utilizaram-se as linguagens de programação C\# e javascript. Usou-se a engine Unity 3D, uma ferramenta de desenvolvimento de jogos digitais em geral, assim como softwares de modelagem digital Maya e 3D Studio Max, softwares de efeitos especiais e de animação de cenas como o Adobe After Effects, softwares de edição de vídeo, como o Adobe Première, softwares de tratamento de imagens, como o Adobe Photoshop, e softwares de ilustração digital, como o Adobe Illustrator. Também é costume da equipe utilizar softwares livres, como o DAZ, para a animação de personagens.

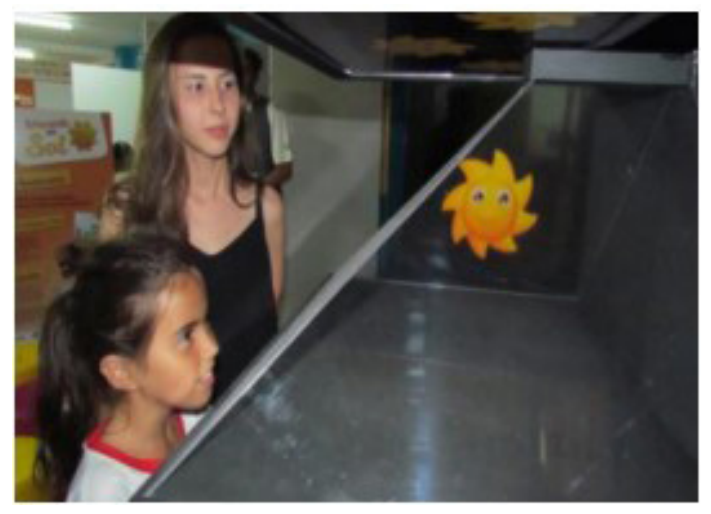

Figura 1: Estrutura holográfica apresentando o Sol, personagem que convidava o público a conhecer a exposição interativa. Fonte: Adriana Oliveira.

\section{Narrativa Digital 3D Ensolarando}

A segunda atividade apresentada na exposição interativa foi uma animação digital em 3D. A atividade teve a intenção de narrar para as crianças, de forma lúdica e atraente, a importância do Sol como fonte de energia e vida na Terra. Para desenvolver essa narrativa, a equipe de designers e pedagogas realizou pesquisas de preferências de representações com crianças da faixa etária escolhida. Essa pesquisa (Figura 2) foi fundamental para o sucesso da atividade, pois, a partir dela, foi possível perceber nuances de preferências de representação gráfica - como preferências de cores, formas, expressões faciais, dentre outros -, como também expectativas quanto a ritmo e ênfase narrativa - velocidade de cenas e áudios, etc. A partir dos achados desta pesquisa, foram introduzidos os personagens Vitor, Sofia e Júlio - cada qual com sua personalidade, como forma de estabelecer um elo entre usuário - criança - e personagens.

Após a definição do escopo da narrativa, um roteiro técnico foi elaborado e, a partir dele, foram modelados os personagens e ambientes a serem exibidos. A equipe gravou os áudios no próprio estúdio do NUCOM/UniCarioca. Por fim, a montagem e efeitos especiais da animação completa foram realizados. Uma animação 3D simula a profundidade por meio da estereoscopia, recurso em que a mesma imagem é exibida para o olho direito e esquerdo, porém, para cada olho, a imagem sofre um ligeiro deslocamento. Por isso, a exibição desta narrativa digital foi feita utilizando uma TV 3D. O público usou óculos especiais para que o efeito 3D (estereoscopia) de fato causasse o impacto desejado, como pode ser observado na Figura 


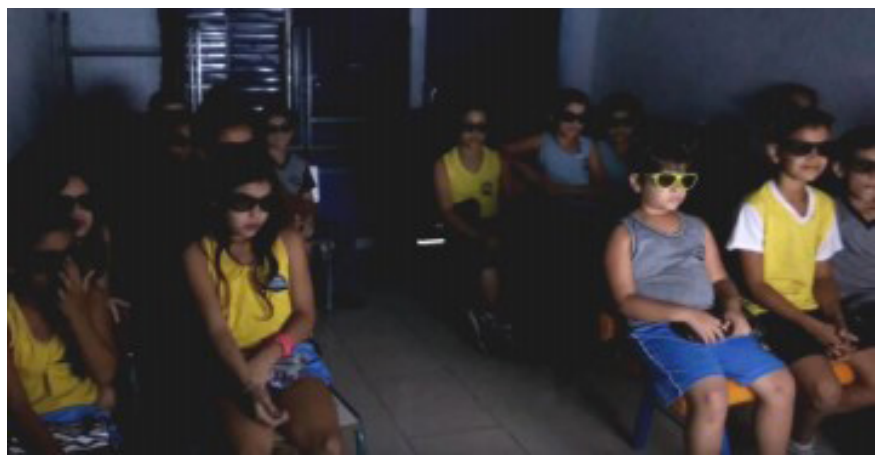

Figura 2: Crianças assistem ao vídeo. Em seguida, respondem a uma pesquisa sobre as preferências de representação visual dos elementos da narrativa. Fonte: Adriana Oliveira.

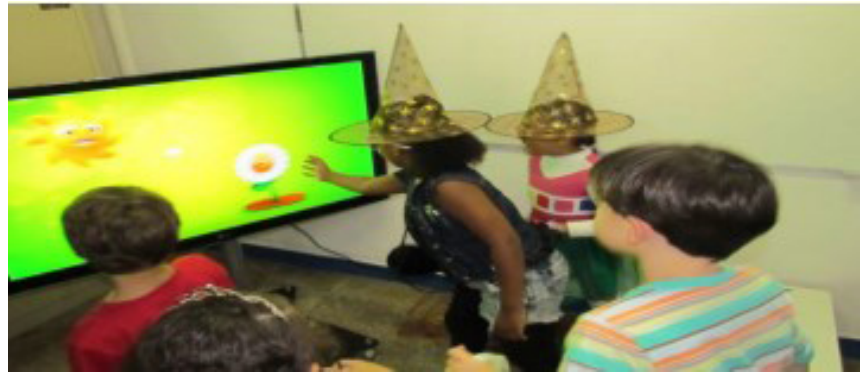

Figura 3: Público experimenta a narrativa digital (vídeo 3D estereoscópico). Fonte: Adriana Oliveira.

\section{Dispositivo de realidade virtual SOLUZ}

As crianças foram instigadas, também, a conhecer os benefícios do Sol para a vida na Terra através de uma experiência imersiva baseada em Realidade Virtual. Foi desenvolvido um jogo interativo em que as crianças eram levadas a responder a certas perguntas por meio de um dispositivo de realidade virtual. Para favorecer a imersão e o entusiasmo na experiência do jogo, as crianças usaram um "capacete" com áudio e vídeo (Figura 4). Este capacete transportava o usuário para o mundo virtual por meio do uso da estereoscopia, recurso já mencionado, e também por meio do recurso de sensor de movimento, dispositivo que faz a imagem se mexer de acordo com a posição e movimento da cabeça do usuário. Pedagogicamente, a partir da interação visual e auditiva da criança, esta atividade também favorece a percepção, trabalha a lateralidade, a identificação de elementos e a noção espacial.

O jogo foi cuidadosamente desenvolvido pela equipe NUCAP com base em pesquisas a respeito de formas mais leves de representação imersiva - técnica de representação em Low Polly - modelagem representada por meio de uma quantidade relativamente pequena de polígonos (Figura 5) em 3D, que favorece uma renderização mais rápida para jogos digitais. 


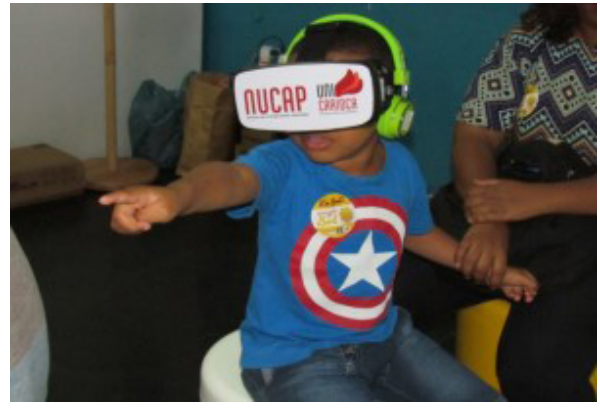

Figura 4a: Criança experimenta, por meio de um capacete, o jogo SOLUZ. Fonte: Adriana Oliveira.

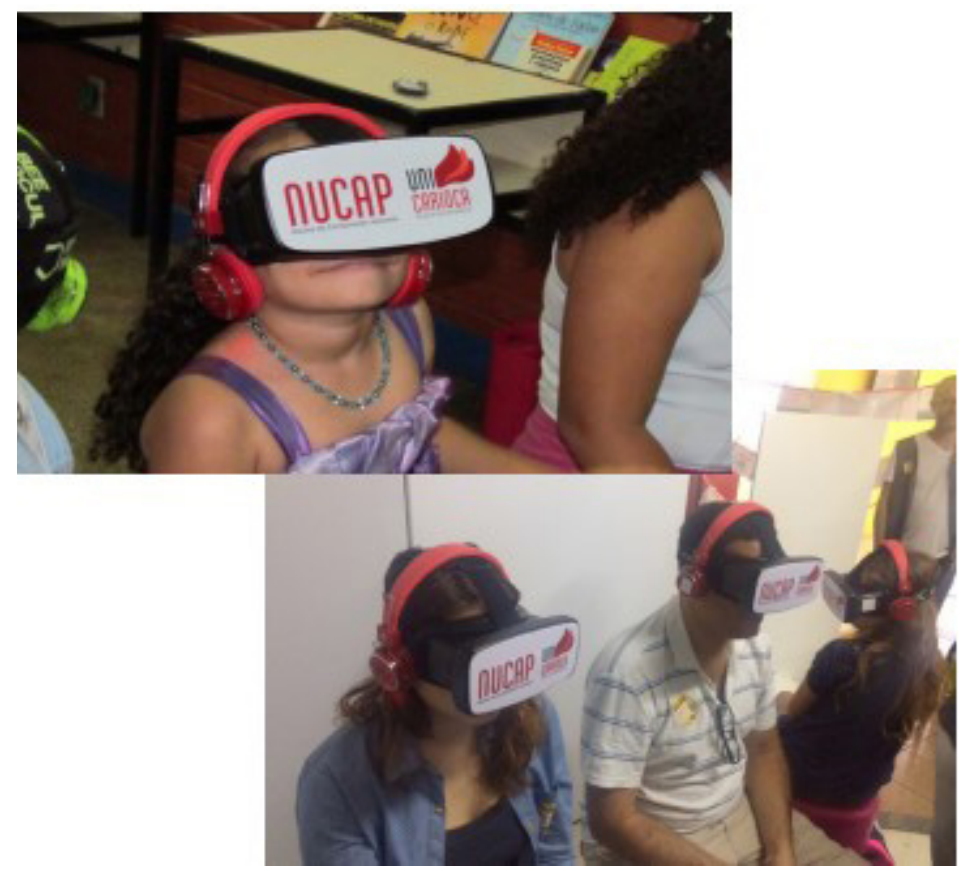

Figura 4b: Crianças experimentam, por meio de um capacete, o jogo SOLUZ. Fonte: Adriana Oliveira.

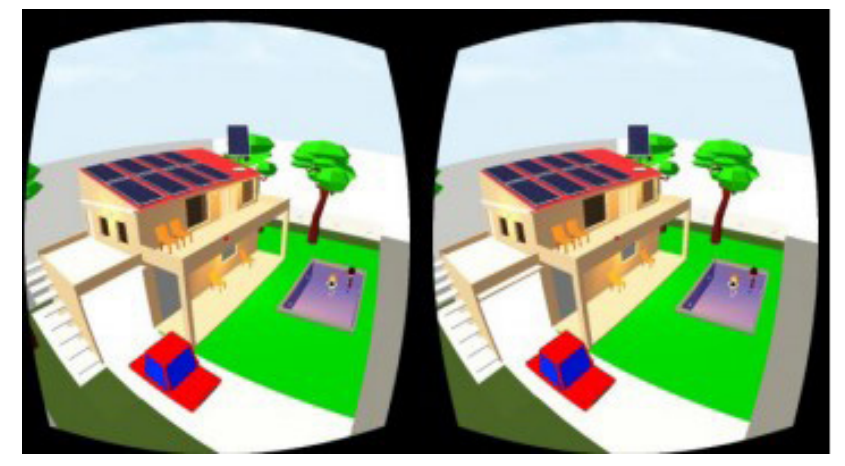

Figura 5: Representação dos objetos de um dos cenários do jogo por meio da técnica Low Polly. Fonte: Adriana Oliveira. 


\section{Leap Motion Uma Ajuda para Vovó Vera}

Foi proposta também uma outra atividade digital interativa, dessa vez por meio de sensor leap motion, dispositivo que permite a interação com computadores usando apenas gestos. No jogo Uma Ajuda para Vovó Vera, o sensor reconhece os movimentos das mãos do usuário e os traduz para o jogo em tempo real, dando a sensação de o jogador estar com suas mãos imersas no ambiente virtual. Portanto, nesta atividade, o usuário foi instigado a conhecer os benefícios do uso e do manejo da energia solar, ajudando a Vovó Vera a montar uma placa solar em seu sítio (Figura 6). A equipe NUCAP pesquisou e desenvolveu integralmente este jogo que, além de abordar a temática da energia solar, também trabalha a psicomotricidade e habilidades sensório-motoras por meio de recursos digitais.

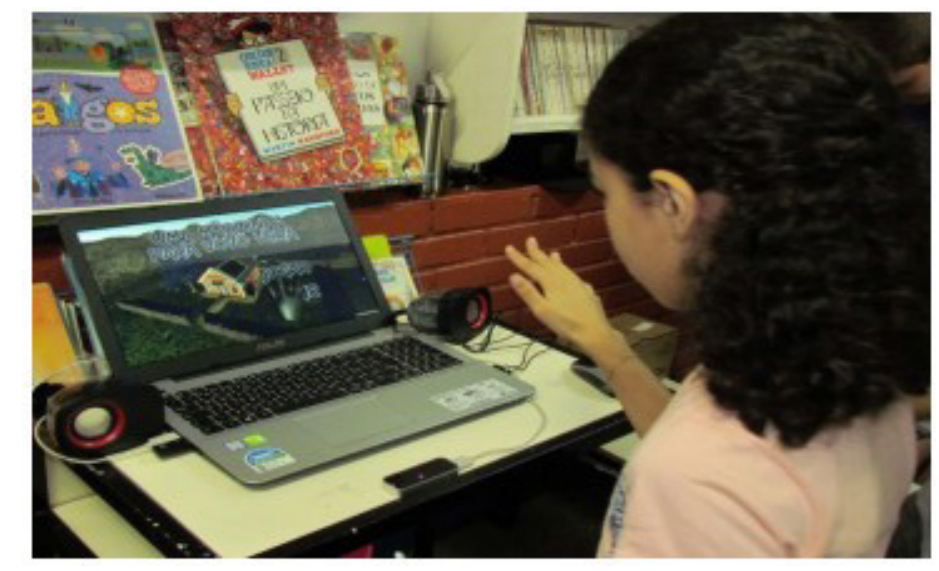

Figura 6: Criança interage com o jogo Uma ajuda paraVovó Vera. Fonte: Adriana Oliveira.

\section{Jogo de trilha digital Trilha do Sol}

A última atividade digital interativa tinha como objetivo desafiar o usuário a testar os conhecimentos aprendidos na exposição. Por meio de um jogo de perguntas e respostas, que propunha uma competição saudável entre os participantes (figura 7), testamos o que foi aprendido durante as outras atividades que abordavam a temática do Sol como fonte de energia, luz e vida na Terra.

O Trilha do Sol é um jogo virtual de tabuleiro que utiliza o mouse e o teclado do computador para que os jogadores acionem o dado e respondam às perguntas propostas. As perguntas são de múltipla escolha e foram produzidas de acordo com o conteúdo trabalhado nas outras atividades do evento. Logo, foi gerado um banco de dados sobre diferentes questões abordadas nas atividades anteriores que eram aleatoriamente acessadas pelo jogo.

A equipe NUCAP desenvolveu integralmente este jogo e vale ressaltar que, além de ter sido utilizado como um método de avaliação das atividades interativas propostas nesta exposição, este recurso foi elaborado para poder se adaptar a outros temas, funcionando, também, como recurso dinâmico e divertido de avaliação de conhecimentos. 


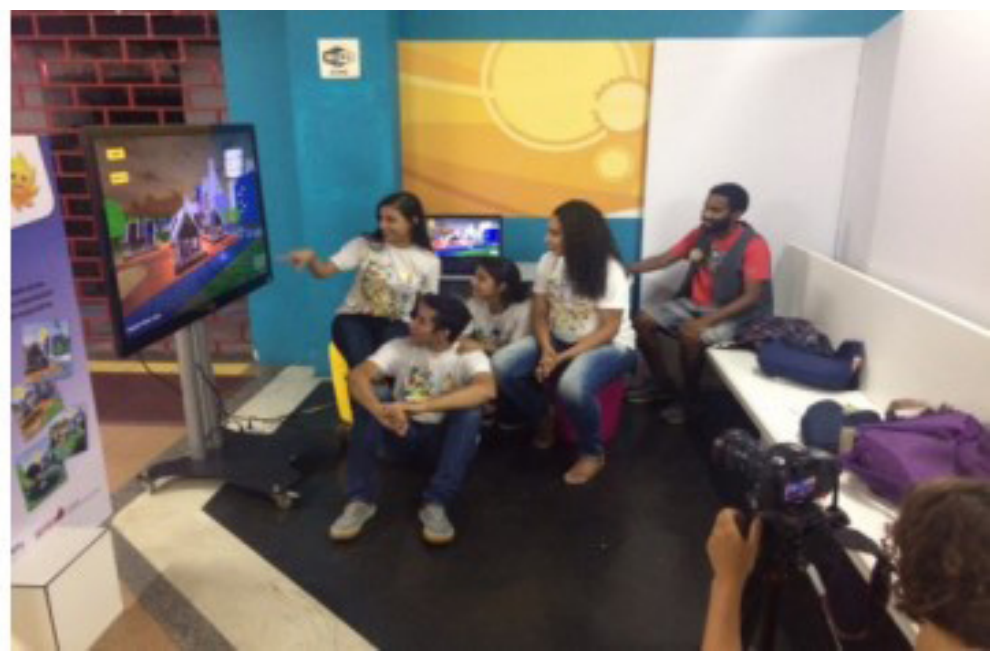

Figura 7: Participantes vivenciam o desafio das perguntas e respostas do Jogo da Trilha. Fonte: Adriana Oliveira.

\section{Atividades autorais: colagens e prototipagem de pirâmide holográfica}

Após percorrer as 5 atividades digitais e aprender sobre a importância do Sol para a vida na Terra, as crianças foram estimuladas à autoria de objetos, colagens e desenhos. Uma mesa com diferentes recursos expressivos estava à disposição, e monitores-bolsistas (do curso de Pedagogia) estimulavam os pequenos a deixarem um registro da experiência vivida. Em outra mesa, foram dispostos recortes de acrílico que, dobrados da forma correta, transformaram-se em minipirâmides holográficas. As crianças construíram suas próprias pirâmides e puderam levá-las para casa como estímulo à perpetuação da apreciação de holografias que, agora, podem ser vistas utilizando a pirâmide acoplada a um celular. Também foi disponibilizado no youtube o vídeo holográfico do SOL para que elas possam assistir de qualquer lugar utilizando sua pirâmide.

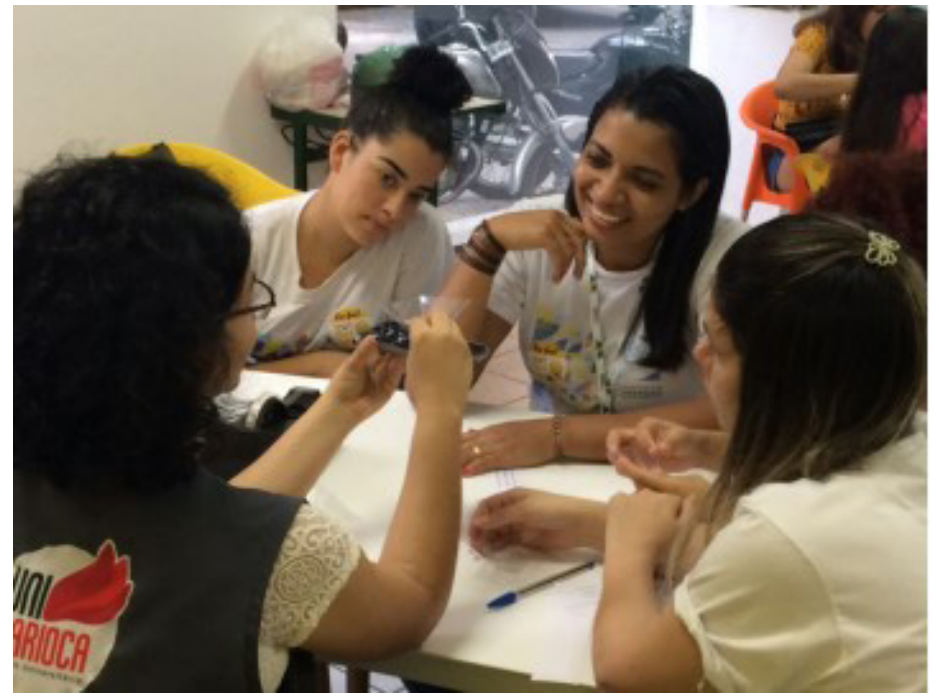

Figura 8a: Visitantes experimentam as atividades não digitais de autoria de objetos e desenhos.Passeando pela exposição interativa. Fonte: Adriana Oliveira. 


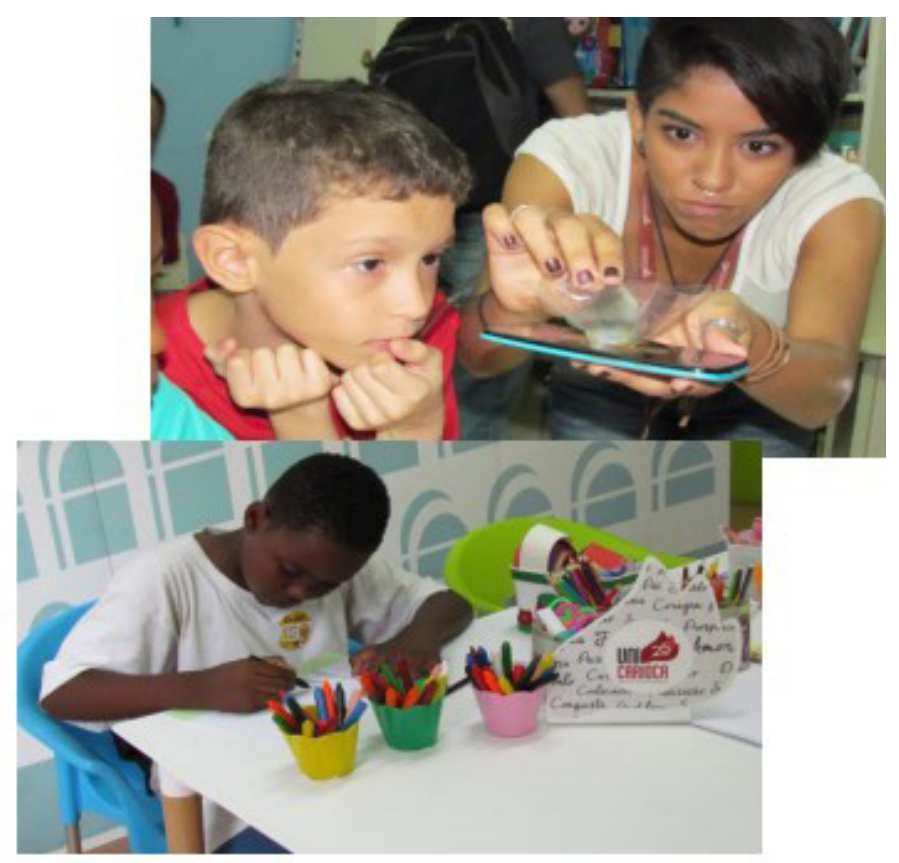

Figura 8b: Visitantes experimentam as atividades não digitais de autoria de objetos e desenhos.Passeando pela exposição interativa. Fonte: Adriana Oliveira.

\section{Passeando pela exposição interativa}

Como comentado, a dinâmica da experimentação da exposição interativa foi idealizada para ser percorrida por meio de percurso fixo no qual os usuários seguiam uma sequência determinada de atividades.

A exposição interativa Brincando com o Sol foi vivenciada por crianças em dois eventos bem diferentes: um no Colégio Pedro II - campus São Cristóvão I - e outro no lounge do Centro Universitário Carioca (UniCarioca), na unidade situada no Rio Comprido (locais situados na cidade do Rio de Janeiro). Durante esses dois eventos, foram distribuídas fichas de avaliação para os visitantes, nas quais tópicos específicos foram respondidos com a classificação de bom, regular e ruim, representados por carinhas com expressões: feliz, séria e triste, respectivamente.

\section{Resultados}

\section{Vivência 1: exposição interativa em espaço de sala de aula}

Durante uma feira literária infantil no Colégio Pedro II, foi disponibilizada uma sala para realizar a exposição interativa. A equipe NUCAP deslocou e montou no local do evento todos os equipamentos necessários para realizar a exposição. As atividades foram todas dispostas num mesmo ambiente, cada uma em um agrupamento de mesas, de modo que qualquer pessoa que entrasse na sala pudesse visualizar o que acontecia em cada uma das atividades. O trajeto da exposição - que foi concebido originalmente como um percurso fixo com atividades organizadas numa sequência linear - por conta da natureza, do tamanho e da logística de instalações elétricas da sala oferecida, deu-se de forma complexa como pode ser visto na figura 9. 


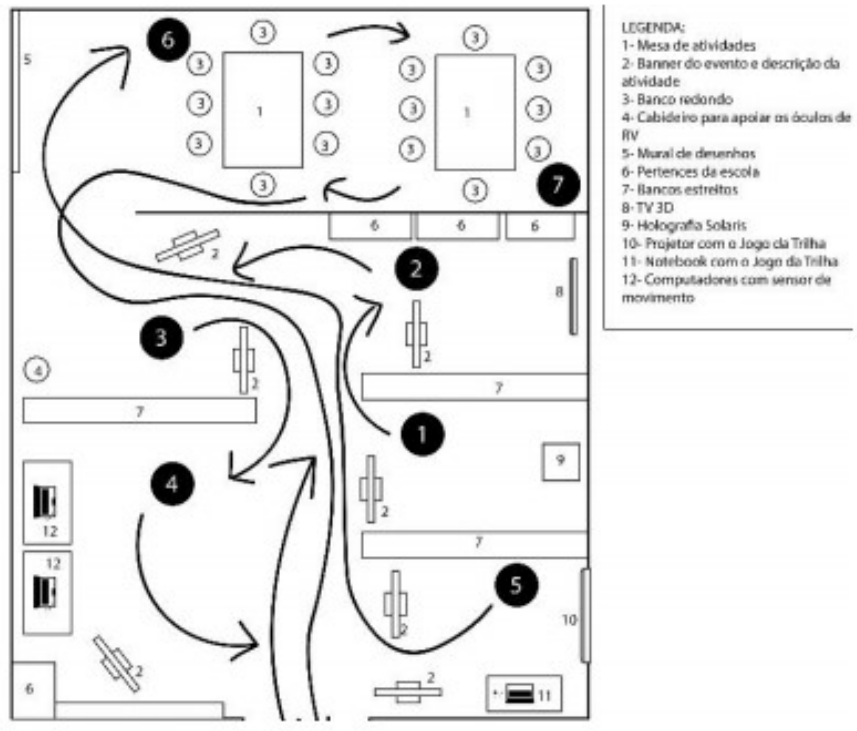

Figura 9: As setas representam o trajeto percorrido pelos visitantes durante a exposição realizada dentro de uma sala de aula. Autoria: Dyene C. Verde e Maíra Roberto.

O evento foi organizado de forma que ao menos um bolsista-monitor estivesse presente em cada atividade. Um outro bolsista-monitor acompanhava o grupo de crianças que experimentaria a mostra. Sua função era organizar a experiência e zelar para que cada atividade fosse experimentada por um limite máximo de 6 crianças por vez, com duração de 5 a 15 minutos.

Como mencionado, o dia do evento coincidiu propositalmente com uma feira literária e, por isso, o colégio recebeu um grande número de visitantes, incluindo muitos adultos, que também participaram do circuito, pois eram familiares das crianças ali presentes.

\section{Apreciação da primeira experiência}

Uma vez que o colégio recebeu muitos visitantes (aproximadamente 1.000), e entravam somente grupos com 6 crianças para percorrer a exposição interativa, deu-se a formação de uma longa fila, fator que fez com que os monitores acabassem permitindo a entrada de mais de 6 crianças em cada grupo. Além disso, como não havia uma separação física e/ou visual entre cada atividade (biombo, por exemplo), logo se notou que as crianças passavam de uma atividade para outra sem finalizar a anterior. Percebemos, também, com o tumulto gerado, que algumas crianças não esperaram sua vez na fila e conseguiram participar isoladamente de algumas atividades, motivadas pela curiosidade em vivenciar as ferramentas digitais.

Por conta do espaço disponível ser inadequado, pelo grande volume de participantes em pouco tempo (figura 10) e por conta do circuito original proposto não ter sido seguido, o resultado não foi satisfatório. Isso ficou evidente na atividade de perguntas e respostas - atividade proposta para testar o conhecimento aprendido - quando percebemos que várias crianças não sabiam responder a algumas questões, pois não haviam passado pelas atividades iniciais. 
Todavia, as crianças que seguiram o circuito corretamente foram capazes de responder às perguntas dos jogos sem grandes dificuldades.

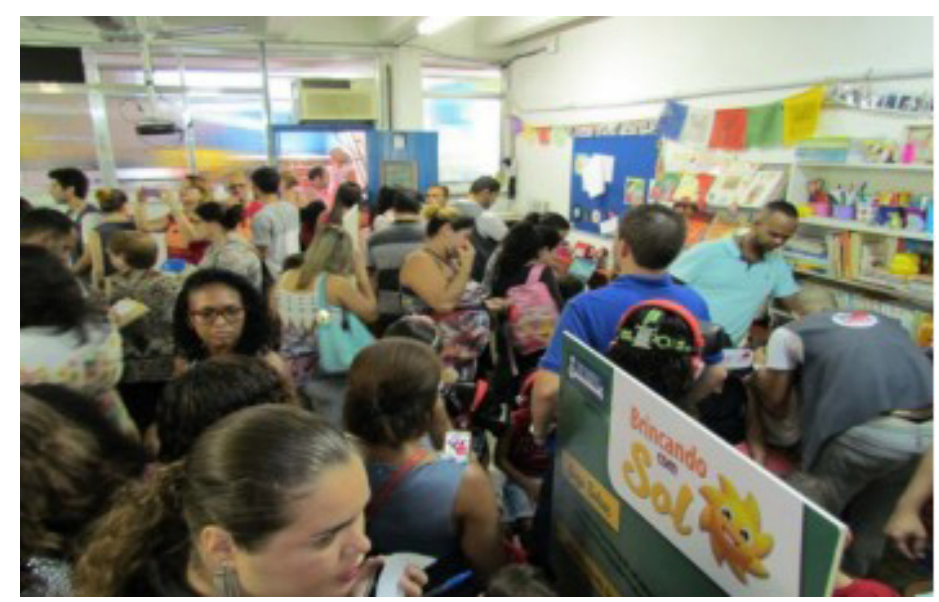

Figura 10: O número elevado de visitantes, a disposição dos objetos na sala e o espaço disponível dificultaram o circuito original. As pessoas passaram a circular livremente pelas atividades, querendo ou não participar de todas. Fonte: Adriana Oliveira.

\section{Vivência 2: exposição interativa em um espaço lounge universitário}

A outra edição do evento foi realizada no lounge da Unidade Rio Comprido da UniCarioca (figura 11). O espaço cedido era maior e não existiam outras atividades acontecendo simultaneamente, por isso foi possível realizar o percurso interativo através de um circuito fixo, como proposto inicialmente. Cada atividade era separada das outras por dispositivos que funcionaram como barreiras físicas e visuais (biombos). $\mathrm{O}$ público-alvo eram crianças do Ensino Fundamental 1, mas outras pessoas puderam participar. O evento foi amplamente divulgado nas escolas da região e ocorreu em dois dias, numa sexta-feira e num sábado (outubro de 2016). Assim como aconteceu no primeiro evento, participaram do circuito crianças e seus familiares, alguns alunos visitantes de uma Instituição que promove Educação de Jovens e Adultos (EJA), além de estudantes da UniCarioca. Foram cerca de 500 participantes.

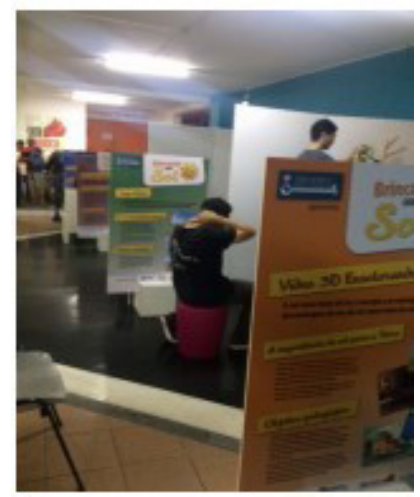

Figura 11: Espaço cedido pela UniCarioca. O circuito pôde ser seguido sem problemas e com o melhor aproveitamento de espaço. Fonte: Adriana Oliveira. 
Ao chegarem ao lounge da UniCarioca, os visitantes foram organizados em uma fila com bancos para sentar e aguardar. Grupos de 4 a 6 pessoas eram convidados a iniciar o percurso, e cada atividade durava no máximo 10 minutos. Os participantes recebiam no início do percurso um adesivo (Figura 12), que já fazia parte do acolhimento e integração do evento.

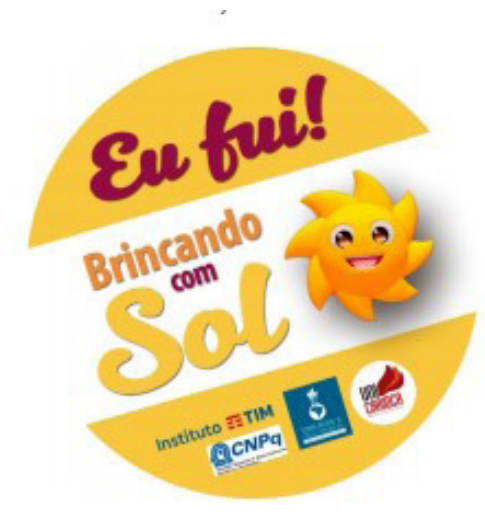

Figura 12: Adesivo do evento. Projeto: Bianca Martins.

\section{Apreciação da segunda experiência}

A segunda edição do evento, em razão de fatores como dimensões do espaço físico, percurso fixo, melhor controle de entrada de visitantes, melhor disposição das atividades, ofereceu aos participantes uma experiência muito mais proveitosa. Eles puderam experimentar cada atividade com tranquilidade seguindo o percurso fixo previamente estipulado. No jogo de perguntas e respostas, a equipe pôde notar que conceitos trabalhados nas atividades prévias tinham sido compreendidos e utilizados como resposta. Nas atividades finais de ilustração e confecção da pirâmide holográfica, foram percebidos depoimentos positivos espontâneos sobre a exposição. Esses fatores podem ser observados nas imagens a seguir.

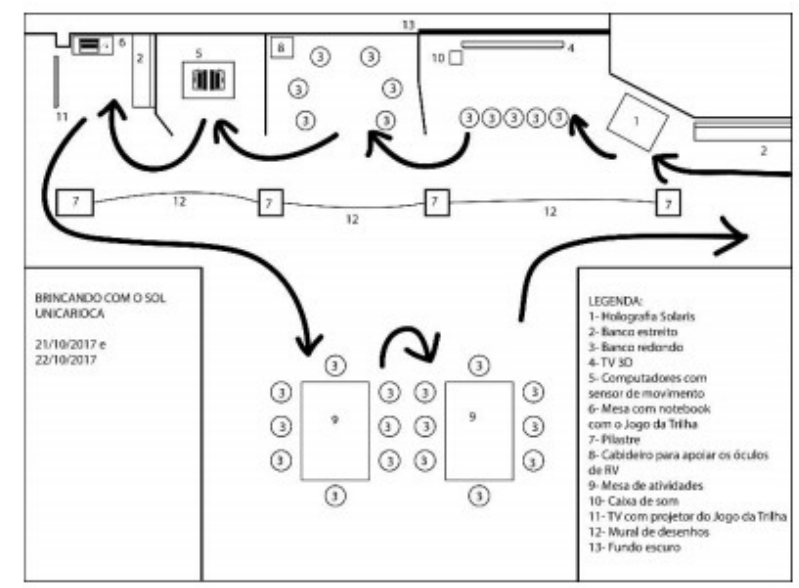

Figura 13: As setas indicam o fluxo de visitantes ao percorrer o percurso fixo da exposição. Notase que desta vez a experiência foi mais organizada. Autoria: Dyene C. Verde e Maíra Roberto. 


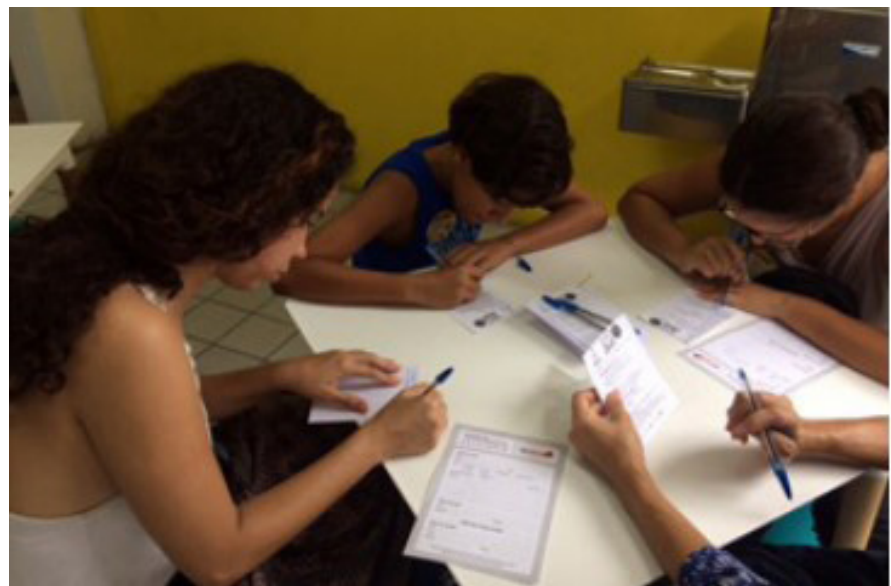

Figura 14: Avaliação realizada por crianças e adultos que vivenciaram o evento. Fonte: Adriana Oliveira.

A ficha de avaliação buscava analisar a opinião dos visitantes em relação a (ao):

- $\quad$ espaço destinado ao evento;

- compreensão do propósito do evento;

- $\quad$ propostas interativas do evento;

- facilidade de uso das ferramentas de RV;

- $\quad$ interação com os jogos digitais;

- holografia;

- narrativa 3D Estereoscópica Digital;

- $\quad$ exposição em forma de percurso.

De todas as fichas de avaliação entregues aos visitantes das duas exposições, um total de 613 nos retornaram a avaliação da exposição interativa Brincando com o Sol.

Abaixo, apresentamos o resultado das avaliações nos dois espaços da exposição (Colégio Pedro II e Centro Universitário UniCarioca): 


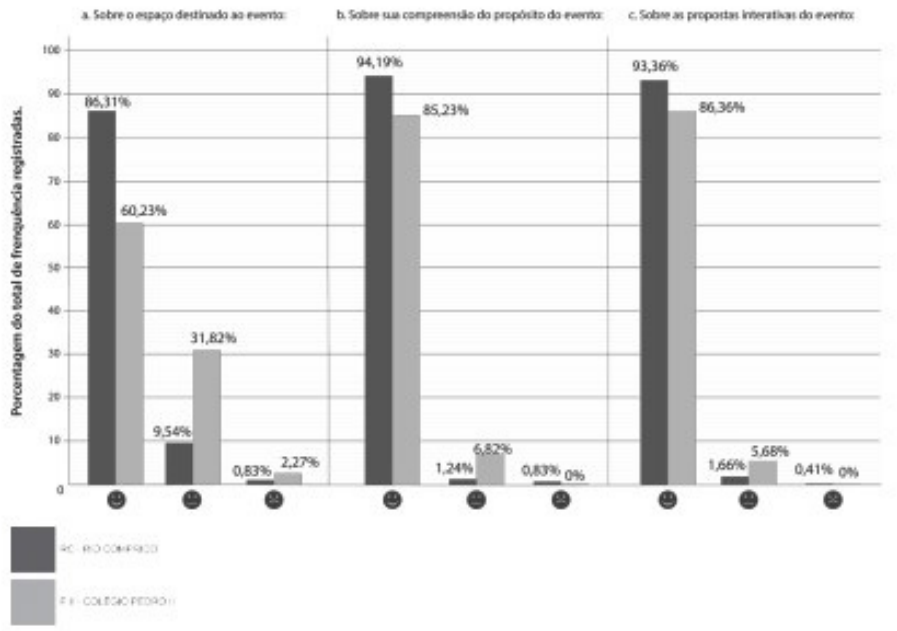

Figura 15: Avaliação da estrutura do evento. Autoria: Maíra Roberto.

É interessante observar que os visitantes nos dois espaços de divulgação científica apreciaram o evento e nos mostraram, em suas respostas, que compreenderam tanto o propósito do evento ( $94 \%$ - UniCarioca e $85 \%$ - Colégio Pedro II) quanto suas propostas interativas (93\% - UniCarioca e 86\% - Colégio Pedro II). No entanto, observou-se que, quando se questionou sobre o espaço destinado ao evento, houve mais respostas positivas dos avaliadores da UniCarioca (86\%) do que do Colégio Pedro II (60\%).

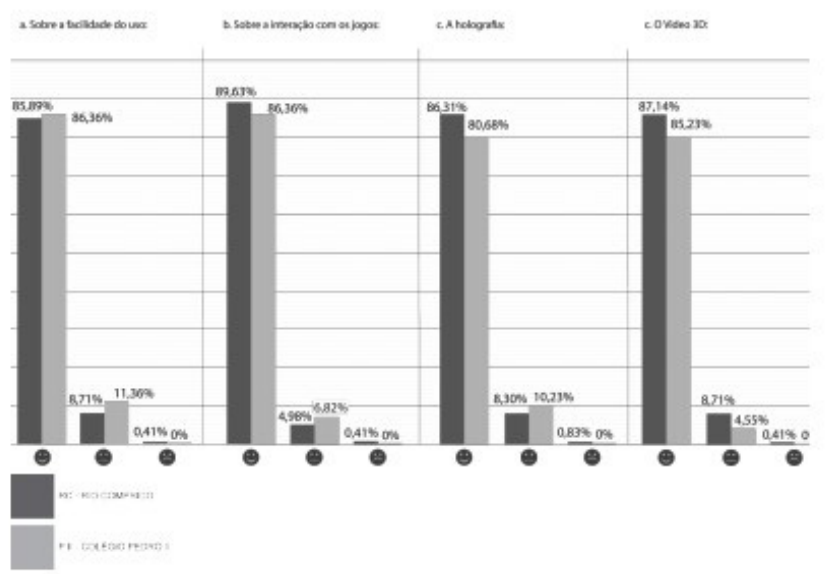

Figura 16: Avaliação das ferramentas de realidade virtual. Autoria: Maíra Roberto. 
Quanto às ferramentas de realidade virtual (facilidade de uso, interação com os jogos, a holografia e o vídeo 3D), tanto os visitantes da UniCarioca quanto os do Colégio Pedro II apontaram respostas positivas. A maioria considerou todos os aspectos apontados como excelentes.

Quanto ao formato fixo de percurso, 90,04\% dos visitantes da UniCarioca identificaram este formato como sendo excelente para a divulgação cientifica; no Colégio Pedro II, a aprovação como excelente foi de 70,45\%, o que mostra que a organização realizada na UniCarioca proporcionou um evento mais organizado no que se refere ao caminho percorrido pelo participante durante visita à exposição.

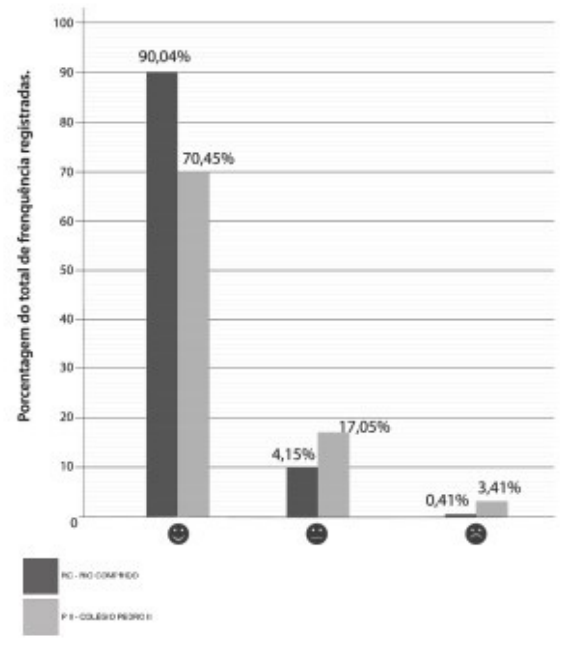

Figura 17: Avaliação do percurso em forma de trilha. Autoria Maíra Roberto.

\section{Considerações Finais}

O expressivo índice de aprovação em ambos os eventos realizados tanto para crianças quanto para adultos mostrou que o uso integrado de tecnologias digitais híbridas em formato de percurso foi motivador e instigante para que o público dos dois espaços de divulgação científica aprendesse que o Sol é uma importante fonte de luz, vida e energia.

É possível concluir que neste tipo de evento educativo (que envolve conhecer um determinado conteúdo por meio de atividades interativas integradas através de um percurso) organizar o espaço de aprendizagem de modo a receber um número menor de pessoas em cada atividade interativa permite aos mediadores uma atenção mais cuidadosa em relação às dúvidas do público. Observou-se que, neste caso, vale mais a pena oferecer ao público a oportunidade de vivenciar as experiências interativas com mais calma e de forma integrada com os demais artefatos tecnológicos.

Finalizando, este trabalho evidencia a importância da imbricação de saberes por meio de uma equipe interdisciplinar quando a proposta é desenvolver experiências educativas que se utilizam de recursos digitais. A equipe composta por designers, educadores e informatas, trabalhando em sinergia, potencializa os conhecimentos destas três áreas resultando em experiências híbridas de aprendizagem (jogos, narrativas digitais e atividades não digitais) que prezam pela escolha cuidadosa da linguagem visual, desafios e interação apro- 
priados ao público-alvo em questão.

\section{Agradecimentos}

Agradecemos a todos os bolsistas do NUCAP na participação do desenvolvimento das ferramentas bem como na monitoria das atividades propostas e apresentadas na exposição Brincado com o Sol: Adriana Oliveira, Jamile Viana, Karen Salazar, Júlio Andrade, Leticia Alves, Leandro Calazans, Tiago Rocha, Sara Isnardo, Jaime Frajdenberg, Jefferson Lima da Silveira, Jaime Carvalho, Victor Hugo Alves, Yuri Fernandes, Paulo Oliveira, Nelson Botelho, Dyene Cabo Verde, Maira Roberto, Joaquim Eugênio, Pedro Aghina, Gabriel Mól, Lucas Hecth.

Agradecimento especial ao Daniel Machado e Daniel Chelles na participação da presente pesquisa. Agradecemos também ao financiamento concedido para o desenvolvimento do projeto ao MCTI/CNPQ/SECIS/ InstitutoTIM e a UniCarioca.

\section{Fomento}

- UniCarioca - Bolsas de Iniciação Científica dos alunos do NUCAP

- MCTI/CNPQ/SECIS/InstitutoTIM - Processo No. 445900/2015-6

- Coordenador: Ana Paula Legey de Siqueira

\section{Contato dos autores}

Bianca M. R. Martins | maildabia@gmail.com Andre C. Espírito Santo | asanto@unicarioca.edu.br Antônio C. A. Mól | amol@unicarioca.edu.br Ana P. Legey | asiqueira@unicarioca.edu.br

\section{Referências Bibliográficas}

ABED. Censo EAD. BR: Relatório Analítico da Aprendizagem a Distância no Brasil 2012. Curitiba: Ibpex, 2013.

CAMBRE, M. Museos interactivos de ciencia y tecnología en América Latina. In: MASSARANI, L. (Org.). RedPoP: 25 años de popularización de la ciencia en América Latina. Rio de Janeiro: Museu da Vida/Casa de Oswaldo Cruz/Fiocruz: RedPOP; Montevidéu: UNESCO, p. 41-50, 2015.

CAZELLI, S. et al. Tendências Pedagógicas das Exposições de um Museu de Ciência. In: Atas do II Encontro Nacional de Pesquisa em Educação em Ciências. São Paulo: Valinhos, 1999.

CAZELLI, S. Jovens nos museus: quem são, aonde vão e com quem visitam?. In: DALBEN, A.; DINIZ, J.; LEAL, L.; SANTOS, L.. (Org.). Convergências e tensões no campo da formação e do trabalho docente. Belo Horizonte: Autêntica, 2010.

CHELLES D; LEGEY, AP; MARINS ER; MOL, ACA; SANTOS-OLIVEIRA R. Nuclear Pharmacy And Virtual Reality: Coupling Technology In: Supporting Of Learning Simulated Interface For Education In Brazil. Acta Farmacéutica Bonaerense, v. 31, p. 782-784, 2012.

FREITAS, V.; MOL, ACA; LEGEY, A. P. Mono or 3D production for scientific dissemination of nuclear energy applications. In: 2011 International Nuclear Atlantic Conference. Belo Horizonte: INAC, 2011.

FICHEMAN, I. K.; CORRÊA, A.G.D.; SAUL, J.A.; BIAZON, L.; CAMARGO, M.A.; MANTOVANI, M.S.M.; ZUFFO, M.K.; LOPES, R.D. Uma Aventura no Espaço com a Nave Mário Schenberg: Ambiente Colaborativo em Realidade Virtual para Aprendizagem de Ciências. In: Anais do XIX Simpósio Brasileiro de Informática na Educação (SBIE), 2008, Fortaleza, p. 746-755, 2008.

FRIEDMAN, A. J. The extraordinary growth of the science-technology museum. Curator, v. 1, p. 63-75, 2007.

KISHIMOTO, T. M. Jogo, brinquedo, brincadeira e educação. São Paulo: Cortez; 1996.

LEGEY, A. P.; REIS, A. B.; PASSOS, CA; FREITAS, V.; ROLANDO, R. F.; Mol, ACA. Framework Para Desenvolvimento De Jogos Computacionais Educativos. Revista de Ciência e Tecnologia. , v.4, p.83 - 101, $2013 a$. 
LEGEY AP, SÁ, FSG, MACIEL, BB, BERNARDO, TCM, CHELLES, DR , PASSOS, CA, MOL, ACA. Desenvolvimento de vídeos estereoscópicos 3D para o ensino na área médica. Revista de Ciência e Tecnologia, 3(2): 2013b.

LEGEY, A. P.; MOL, ACA; LAPA, C. M. F.; LIMA, T.; PAULA, V. M.; LUCENA JUNIOR, I.; AUGUSTO, H. Digital game for education and dissemination of nuclear energy applications. In: International Nuclear Atlantic Conference, 2015, São Paulo. INAC, 2015.

MACEDO, L. Aprender com jogos e situações-problema. Porto Alegre: Artes Médicas, 2000.

MARTINS, B.; COUTO, R. Enfoques sobre o desenvolvimento de materiais educativos em múltiplas mídias: diretrizes do processo de Design. In: Anais do 1o Colóquio de Pesquisas em Educação e Mídia, 2007.

Aprendizagem Baseada em Design: uma pedagogia que fortalece os paradigmas da educação contemporânea digitais. In: 7th Information Design International Conference, 2015, Brasília. Proceedings of the 7th Information Design International Conference. São Paulo: Editora Edgard Blücher, 2015.

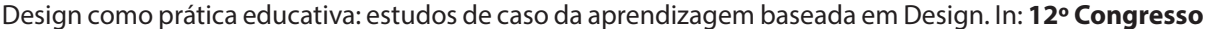
Brasileiro de Pesquisa e Desenvolvimento em Design, 2016, Belo Horizonte. Blucher Design Proceedings. São Paulo: Editora Blucher, 2016. v. 2. p. 5625.

MARTINS, B; NOLASCO-SILVA, L. O professor-designer de experiências de aprendizagem: autoria docente e uso recursos lúdicos na formação de professores. Revista Carioca de Ciência, Tecnologia e Educação, v. 2, 2017.

MATTAR, J. Games em educação - como os nativos digitais aprendem. São Paulo: Pearson, 2009.

McMANUS, P. Topics in museums and science education. Studies in Science Education, v. 20, p. 157-182, 1992.

MJV. Gamificação. Disponível em http://www.mjv.com.br/gamificacao. Acesso em: 30 NOV 2015.

OLIVEIRA, A.; Mol, ACA; Land, V, TEIXEIRA, A LEGEY, A.P.;. Dinâmica de uso de Jogos Digitais para apoiar o processo ensino/aprendizagem em crianças com transtorno de atenção: um estudo de caso do jogo da memória digital In: Congresso - Recursos Digitais na Educação, 2015, São Paulo. 2015.

PADILLA, J. Conceptos de museos y centros interactivos. In: CRESTANA et al. (Orgs.). Educação para a ciência: curso para treinamento em centros e museus de ciência. São Paulo: Editora Livraria da Física, p. 113-142, 2001.

SALAZAR, K, MOL ACA, COTELLI, A, SILVEIRA, J. Desenvolvimento de um jogo de tabuleiro educacional. In: III Congresso de recursos digitais na educação. São PAULO. NOVEMBRO. 2015.

SALAZAR, K; SILVEIRA, JL; OLIVEIRA, A. MOL, ACA, LEGEY, AP, Development of a Digital Educational Board Game. SBGAMES, São Paulo, 2016.

SANTAELLA. L. Desafios da ubiquidade para a educação. In: Revista Ensino Superior. Unicamp. Disponível em: www.revistaensinosuperior.gr.unicamp.br/artigos/desafios-da-ubiquidade-para-a-educacao . Acesso em: abril de 2017.

VIEIRA, V.; BIANCONI, M.L., DIAS, M. Espaços não-formais de ensino e o currículo de ciências. In: Revista Sociedade Brasileira para o progresso da Ciência (SBC), vol. 57, n० 4, 2005.

VENDRUSCOLO, F.; DIAS, J.A.; BERNARDI, G.; CASSAL, M.L.; Escola Tri-legal - Um ambiente virtual como ferramenta de apoio ao Ensino Fundamental através de jogo educacionais, Colabor@ - Revista digital da CVA-RICESU, V. 3, N. 9, 2005.

WINNICOTT, D. O brincar e a realidade. Rio de Janeiro: Imago, 1975.

ZABALA, A.; ARNAU, L. Como aprender e ensinar competências. Porto Alegre: Artmed, 2010. 